\title{
La Colección de Arte Latinoamericano de la Universidad de Essex (UECLAA)*
}

Valery Fraser

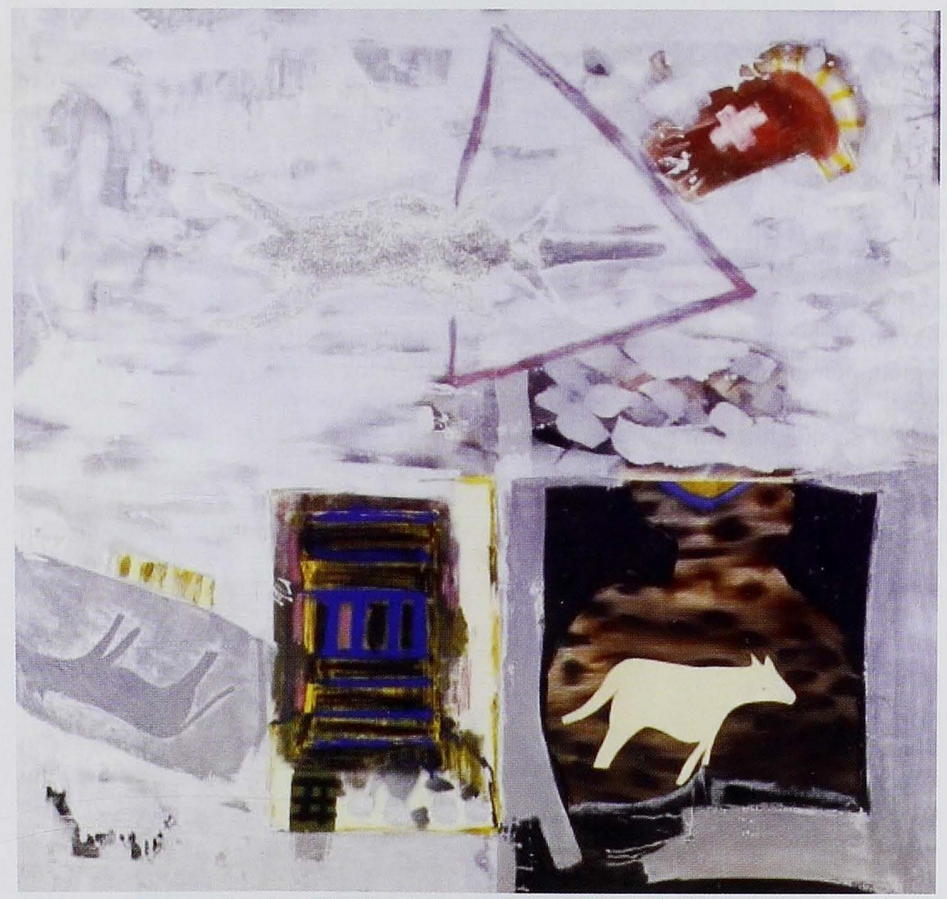

Siron Franco. Memória, 1992, óleo sobre lienzo, donado por Charles Cosac.

Este artículo ofrece una breve reseña de la Colección de Arte Latinoamericano de la Universidad de Essex (UECLAA) refiriéndose a su historia, a su flamante catálogo en la Internet y al proyecto de su nuevo local (realizado en colaboración con la organización contemporánea de artes visuales FIRSTSIDE). 


\section{ORÍGENES DE UECLAA}

La Colección de Arte Latinoamericano de la Universidad de Essex fue creada en 1993 a partir de la obra del destacado artista brasileño Sirón Franco, Memoria (1992), [fig.1] donada por Charles Cosac, un estudiante del Departamento de Historia y Teoría del Arte. Memoria es una pintura intrigante y multivalente: externamente atrae al espectador por su brillante superficie plateada, pero si se analiza mejor, la obra no se refiere a una simple evocación como su nombre lo plantea. Los detalles sugieren dos nefastos aspectos de la participación del Brasil en la economía global: la fauna olvidada y el comercio ilegal de pieles en la selva tropical amazónica. La superficie plateada de la pintura muestra un ataúd de niño que evoca la tragedia ocurrida en 1987, en el distrito de Goiania, y que el artista presenció, cuando una compañía internacional inundó ilegalmente el mercado con latas de cesio, sustancia de apariencia brillante que atrajo la atención de los niños de la localidad que jugaron inocentemente con ellas. Este incidente ocasionó la muerte de muchos menores y dejó a otros, hasta la actualidad, con serios problemas de salud. Memoria de Franco es una obra desafiante cuya fuerza simbólica sirvió como paradigma de las siguientes adquisiciones realizadas por los directivos encargados de incrementar la nueva colección del Reino Unido. Conocer profundamente una obra artística implica investigar sus cualidades formales y las ideas que residen detrás de ella, para luego entender e interpretar el contexto estético e ideológico en la que ella se ha gestado. Esto es lo que la UECLAA desea hacer.

A partir de esta donación inicial la UECLAA ha incrementado su colección en más de 700 obras de arte en diversos soportes y lenguajes artísticos de varios países de la región, poniendo énfasis en trabajos realizados en los últimos cincuenta años. Casi todos los países de Latinoamérica están representados. Las primeras donaciones fueron las que hicieron posible que la UECLAA posea obras de algunos de los más importantes artistas del arte moderno y contemporáneo tales como Matta, Tunga, Senise, Cruz-Diez, Kuitca, Szyszlo y Tamayo; piezas con las que la colección se consolidó. En muchas ocasiones los donantes escogieron las pinturas que coincidían

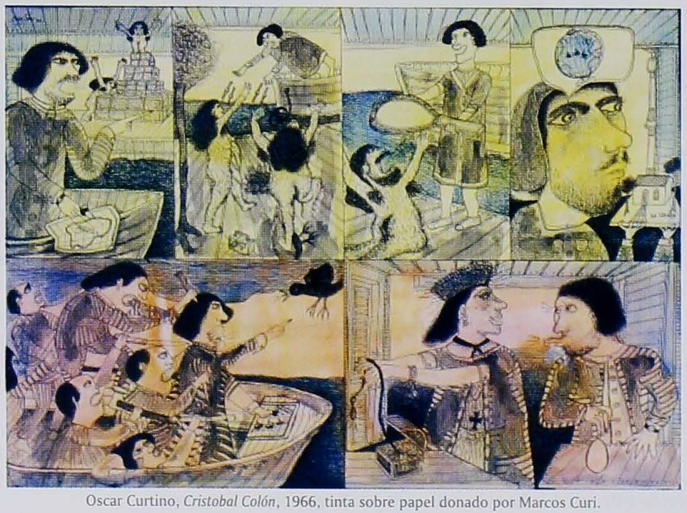




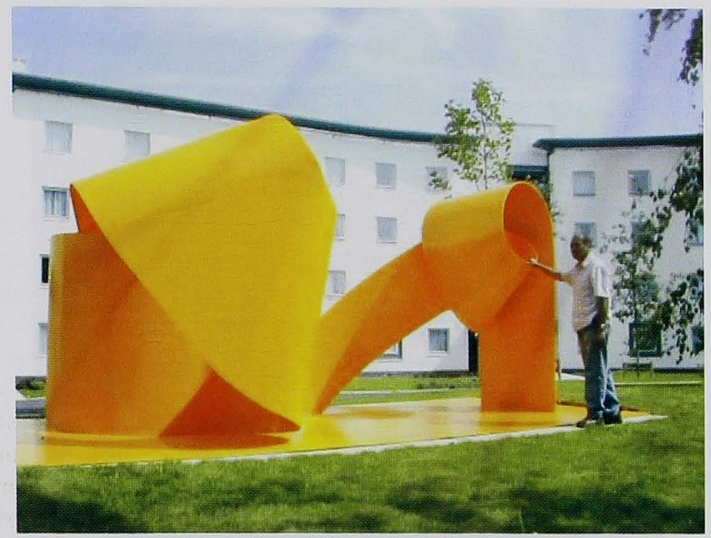

Armando Varela, Tu y yo, 2004, acero pintado, donado por el artista.

con la idea de una colección de Arte Latinoamericano en Europa y de la historia paradójica que relaciona a ambos continentes.

Un buen ejemplo es la primera donación de Marcos Curi, Director del Museo de Arte Contemporáneo de Buenos Aires, quien cedió un dibujo a tinta del artista Oscar Curtino titulado Cristóbal Colón (1966) [fig.2]. La obra realizada a manera de tira cómica muestra a Colón ambicioso y lascivo, a los conquistadores apuñalándose unos a otros a traición, pugnando por controlar los nuevos territorios, mientras que, por otro lado, los nativos crédulos reciben con agrado relojes inservibles y adoran una pirámide construida de objetos importados. La idea propuesta es el diálogo entre las culturas a través del tiempo y del espacio, un tema importante en la colección. Los ejemplos incluyen Tres Caminos (1995) de Daniel Senise, donde las sombras de dos mujeres están unidas por líneas entrelazadas como si estuvieran enfrascadas en una interminable conversación; y la monumental obra de Armando Varela Tu y Yo (2004) [fig.3], en la que una cinta de acero de rizos gigantes se enrosca evocando a una pareja que se abraza.

Otro argumento importante para que una colección sea considerada en el Departamento de Historia del Arte de la Universidad es que las obras hagan explícita referencia al arte del pasado. Obviamente esto incluye un número de citas e interpretaciones ingeniosas de iconos del arte europeo, piedra angular de la historia del arte tradicional. Indiscutiblemente La Venus (1992) de Ramiro Arango, es una parodia de la Venus de Urbino de Ticiano que sustituye al personaje por voluptuosas calabazas. El O libro Velásquez (1996), de Waltercio Caldas, replica un volumen de Velásquez, cuyo texto es ilegible y las imágenes se reconocen como pertenecientes al famoso pintor español aunque estén alteradas. La Historia de Arias (1998) [fig.4] de Fernando Arias, está hecha de otro icono: la introducción de la Historia del Arte de Ernest Gombrich, con la diferencia de que en la obra el tomo está atornillado y es, por lo tanto, inaccesible. Sin embargo se proveen folletos que documentan la obra realizados por el autor. Live Red Tree (1990) de Ofelia Rodríguez, se refiere a algunos iconos centrales del arte de Latinoamérica en lugar del europeo: en la parte central de 


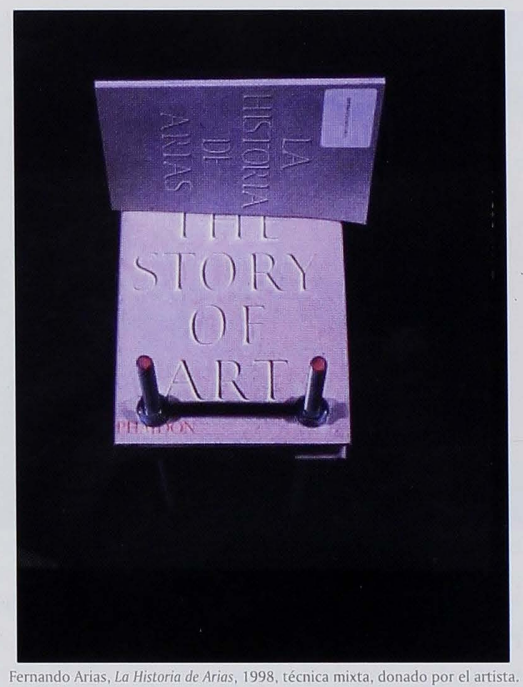

un sarcófago hay un doble retrato de Frida Kahlo y Diego Rivera. Cuando la artista recaló en una escuela de los Estados Unidos descubrió con sorpresa que sus tutores tenían noticias sobre el arte en Latinoamérica.

Otras obras reconocen el arte del pasado precolombino, un área importante de investigación dentro del departamento de historia de Essex. Especialmente apropiado para su inclusión en la UECLAA fueron los tres siguientes ejemplos: las series de Figuras Prehispánicas (1976) de Rufino Tamayo; Sombra de la Luna (1996) de Fernando Montes y Habitación No 32 (1994) de Fernando de Szyszlo [fig.5].

La UECLAA ha establecido sus lineamientos respondiendo a los intereses de las investigaciones de los docentes y estudiantes egresados del Departamento de Historia y Teoría del Arte. Nuestro primer curador fue Gabriel Pérez Barreiro, un estudiante del doctorado que trabajó los movimientos vanguardistas argentinos de las décadas de 1940 y 1950 , periodo en que se fortalecieron las bases del arte constructivista de Argentina (con artistas como Juan Melé y Giula Kosice) y de Uruguay (como José Costigliolo). Esto hizo posible conseguir donaciones de artistas que habían experimentando situaciones similares en otros países (por ejemplo Carlos Cruz-Diez y Francisco Salazar, de Venezuela; y Edgar Negret y Eduardo Ramírez Villamizar, de Colombia). La actual curadora Gabriela Salgado ha logrado la participación de artistas jóvenes menos conocidos como María Escurra con Leopard Swimsuit (2001) [fig.6]; Renata Podován con Laic III (2002); Marcia Thompson con un trabajo sin título del 2003 y una video instalación de Clemencia Echeverri llamada Cal y Canto (2004). El programa de exhibiciones y residencias de la UECLAA, en un primer momento, adquirió importantes piezas para el Reino Unido, actividad que incrementó sus fondos considerablemente. Entre estas recientes adquisiciones encontramos Poncho (2000) de Esteban Álvarez; Quisiera tener mis tierras propias, 


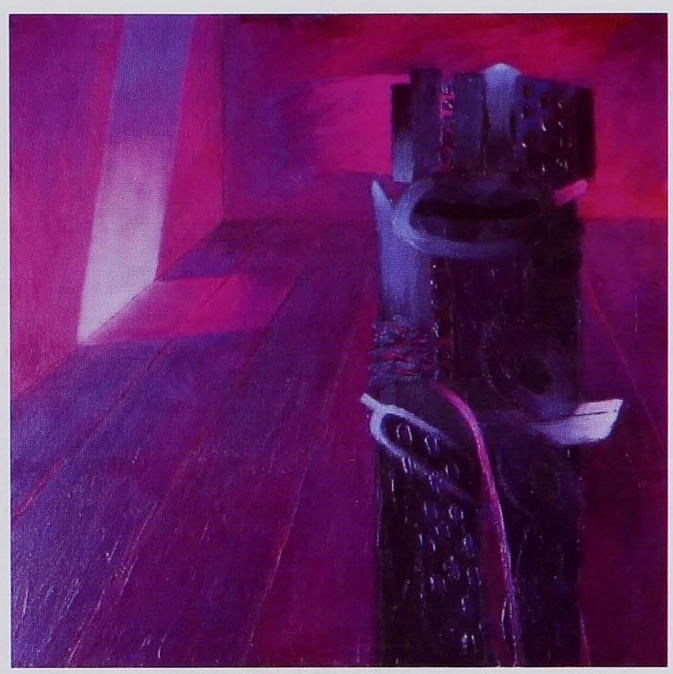

Fernando de Szyszlo, Habitación No.32, 1994, óleo sobre lienzo, donado por el artista.

Juripucio, Jujuy, Argentina (s/f) de Martín Webwe; Holo Olho (1983) de Eduardo Kac y Sombras de Plata (2001) de Demián Flores Cortés.

La política de adquisiciones de la UECLAA es amplia y flexible. Se han aceptado también obras de artistas nacidos fuera de la región, como en el caso de Tomie Ohtake, quien nació en Japón y vive en Sao Paulo, así como las creaciones de artistas de la región que residen en otras partes del mundo (por ejemplo Jaime Gili, nacido en Venezuela pero residente en Londres; o Eduardo Kac, brasilero que vive actualmente en Chicago).

\section{LA UECLAA EN LA INTERNET: www.ueclaa.org}

En el año 2002 una directiva gubernamental del Reino Unido proveyó de una subvención de tres años al Centro de Investigación para las Humanidades y las Artes (AHRB). Los fondos de este programa de recursos se destinaron a elaborar una base de datos y crear una página web que facilitara el acceso del público investigador a la UECLAA. El objetivo era convertir su antiguo catálogo, carente de imágenes, en una base de datos versátil.

Inicialmente sólo el técnico encargado del trabajo comprendió, a diferencia de los demás miembros que formaban parte del equipo, que una base de datos diseñada adecuadamente podría mejorar satisfactoriamente el manejo de la colección. Se diseñó un catálogo sistematizado que integra además de la información de las obras, datos sobre los artistas, imágenes, direcciones y contactos, etc. Por ejemplo, el sistema actual garantiza que no se puede tener completo acceso a una obra sin que se hayan cumplido antes todos los pasos previos (cartas de agradecimiento, valuación 


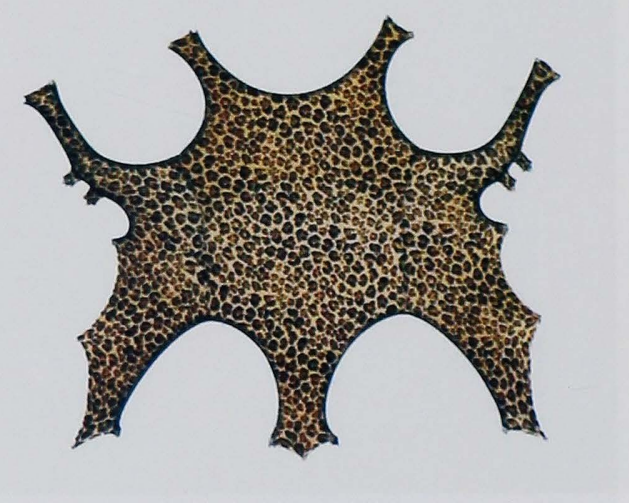

María Ezcurra, Leopard Swimsuit, 2001, instalación, donada por el artista.

del seguro), y que las imágenes no pueden ser tomadas de Internet hasta que no se reciba una autorización firmada por el artista. Además el sistema proporciona otras ventajas de importancia, como una opción con listas de intereses, títulos de exposiciones, etc.

El principal sistema de administración es el catálogo. Su diseño fue desarrollado luego de un detallado estudio del Getty Descriptive Cataloging Good Practice Survey. Además de la información estándar catalogada (fecha de ejecución, técnica, dimensiones, etc.) incluye campos para la interpretación de textos de trabajos de arte individuales, biografías de artistas e información adicional acerca del arte latinoamericano. Una característica especial del catálogo por Internet de la UECLAA es el Artist Statement (Declaración del Artista), donde se incluirán textos cortos de los propios artistas acerca de su trabajo o su trayectoria profesional, una valiosa fuente para los investigadores. Desarrollar un catálogo por Internet que contenga completa información, requiere tener en cuenta un número de preguntas acerca del perfil de los usuarios, tipos de contenido y la estructura necesaria para brindar la información que se requiera. El público objetivo de la UECLAA Online son los estudiantes escolares de secundaria y universitarios, profesores, artistas, críticos de arte, curadores, profesionales de museos y diletantes. Esto significa que debe proveer información útil a especialistas y no especialistas. La ventaja, pero también desafío de la web, es su carácter multidireccional y anárquico: los usuarios acceden, navegan y dejan la página cuando lo desean y por ello es vital que puedan orientarse con facilidad. El catálogo por Internet de la UECLAA se está ampliado e incluye diferentes maneras de búsqueda e información. Los no especialistas pueden indagar en diferentes rutas o utilizar diferentes ítems de investigación. Las categorías de búsqueda son: por artista, por título, por tipos de trabajo, por nacionalidad o por temática. Los temas incluyen géneros (p.e. paisaje, retrato); estilo o movimiento (p.e. abstracción, cinetismo); e ideas (p.e. política, sexualidad). En muchos casos los temas son o serán la ruta de entrada a la UECLAApedia. Este glosario hecho a la medida de la UECLAA incluye también definiciones y términos especializados. 
Aunque se dice que la Internet es democrática, esto es cierto no porque la información que contiene esté al alcance de cualquier persona con acceso a la red, sino porque el administrador no puede controlar el fin que los usuarios le dan. El catálogo por Internet de la UECLAA no ofrece una teoría general o interpretación de sus obras, ya que no sería un material apropiado para entregar en la red, por ser sólo una fracción del Arte Latinoamericano. En efecto esto requeriría una introducción general monolítica al catálogo y aunque se deseara o fuera posible escribir tal cosa, serían muy pocos usuarios podrían elegirían leerla. Lo que mejor puede hacer la web es proveer pequeños y prudentes paquetes de información que puedan ser utilizados para distintos propósitos. Las características del catálogo de MyUECLAA permite a los mismos usuarios seleccionar y agrupar sus artículos y luego desarrollar o no sus propias interpretaciones y teorías: la elección depende de ellos. El catálogo por tanto está diseñado para incluir la más sólida investigación basada en la información sistematizada, de una manera tan fácil de manejar como sea posible. De igual modo el diseño visual del catálogo por Internet trata de dar al arte la misma prioridad y permitir a los usuarios explorar el contenido sin distracción alguna. El diseño asegura también que la website cumpla con la legislación de acceso a Internet del Reino Unido.

Pero el catálogo por Internet o museo virtual no puede ser siempre un sustituto del arte real. Solamente la computadora o el video/arte destinado para verse en la pantalla de una computadora personal puede ser descrita como "real" cuando aparece en el catálogo. (La terminología puede ser muy complicada en este campo: la computadora de arte real es virtual; una vez impresa se torna, por supuesto, en una reproducción). Tomando dos ejemplos peruanos, la escalera gigantesca en Chair in Taquile de Paloma Crousillat, o los ricos colores de Habitación N ${ }^{\circ} 32$ de Fernando de Szyszlo, pueden ser catalogados usando sistemas estandarizados de medición de tamaño y color, pero esto no reemplaza la sensación de pasarse frente a estos cuadros y apreciarlos en directo. Inevitablemente la pantalla crea una falsa impresión de escala y sustituye luz por pigmentos, permitiendo que sea imposible enviar una combinación exacta del color de la pintura. Es importante que la colección tangible de la UECLAA sea tan accesible como lo es virtualmente.

\section{LA UECLAA at Firstside:www. firstside.uk.net}

La UECLAA está ahora comprometida en una sociedad innovadora con Firstside, un centro local de arte muy dinámico ubicado aproximadamente a dos kilómetros del campus en pleno centro de Colchester. Firstside trabaja con arte contemporáneo en todas sus innovaciones así como con exhibiciones y residencias de artistas, coordinando un programa de educación extensiva que involucra locales escolares, colegios y organizaciones comunitarias y fomentando actividades relacionadas al arte en toda la región. La UECLAA ha trabajado internamente con Firstside en los últimos años y su programa anual incluye dos exhibiciones importantes $\mathrm{y} / \mathrm{o}$ involucrando residencias de artistas contemporáneos de América Latina, y dos cortas exhibiciones de trabajo de la UECLAA seleccionadas para coincidir con las importantes exhibiciones. Firstside se encuentra actualmente ubicada en un antigua y pintoresca casa en Colchester, con vigas de madera y techos curvos: un lugar interesante y además sumamente ideal para el arte contemporáneo. La UECLAA no 
tiene un local permanente, a pesar de que una selección de trabajos está dispersa en varios lugares por todo el campus. La solución de estas limitaciones es integrarla y como resultado la UECLAA y Firstside están trabajando juntos en los planos de un nuevo edificio que combinará las actividades de ambas organizaciones. El diseño que ganó el concurso en 2003 pertenece a Rafael Viñoly, [fig.7] con estudio en Nueva York, y desde

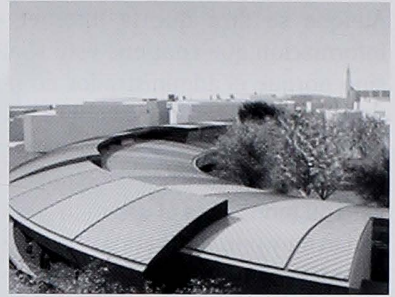

Diseño del nuevo Visual Arts Facility, Colchester Rafael Viñoly Architects, 2005 entonces los planos han sido revisados para adecuarse a las necesidades de ambas partes. El nuevo edificio abrirá sus puertas en el 2007, e incluirá espacios para exhibiciones temporales, un auditorio, y salas para seminarios, cafetería y tiendas, así como un área de exhibición y un centro especial de estudio y de recursos dedicado a la UECLAA. Además, el arte latinoamericano tendrá una notoria presencia en el programa de exhibición en todo el edificio.

\section{ELFUTURO DE LAUECLAA}

La UECLAA es un importante centro de desarrollo. El catálogo por Internet continúa creciendo y en breve se colocarán los cimientos para la construcción del nuevo edificio en Colchester. El próximo nombramiento de un Director Asistente para la UECLAA asegurará el cumplimiento de estos proyectos y la vigencia de la provechosa sociedad con Firstside. Los objetivos de la UECLAA, de su catálogo por Internet y Firstside son todos complementarios. Retornando de nuevo a la primera donación a la UECLAA, Memoria de Siron Franco, es importante reconocer los peligros de la economía global en el arte como en las demás cosas, sin embargo, la globalización también ofrece oportunidades extraordinarias. La UECLAA se propone investigar la complejidad y el significado global del arte Latinoamericano. Firstside apunta a formular un arte diverso y estimulante que se extienda a todas las personas que sea posible. El catálogo por Internet de la UECLAA debe promover esos objetivos. El arte, tanto físico como virtual, puede y podrá emitir luz en nuestras propias vidas, así como también debe desafiar conceptos, abrir puertas y alentar debates en ambos lados del Atlántico y alrededor del mundo. 